\title{
Gravid Uterus Adjusted Maternal Body Weight
}

National Cancer Institute

\section{Source}

National Cancer Institute. Gravid Uterus Adjusted Maternal Body Weight. NCI Thesaurus.

Code C124477.

The maternal body weight adjusted for the weight of the gravid uterus. This is derived by subtracting the gravid uterus weight from the total maternal body weight. 